\title{
A Patient with Proximal Myotonic Myopathy and Parkinsonism
}

\author{
Kon Chu, Jin-Whan Cho, Eun-Chol Song, Beom S. Jeon
}

\begin{abstract}
Introduction: There are two case reports of patients who had proximal myotonic myopathy (PROMM) / myotonic dystrophy (DM) Type 1 and parkinsonism. The combination of myotonic myopathy and parkinsonism is so rare that it may appear to be just a coincidence. However, previous neuropathological examinations of patients who had myotonic dystrophy showed that there were intracytoplasmic inclusion bodies in the nigra and striatum, which raises the possibility that myotonic myopathy may be associated with parkinsonism. In this report we describe a patient with PROMM and a clinically definite parkinsonism to highlight this possibility. Case Report: A 65-year-old man developed proximal muscle weakness, myotonia and atrophy around the age of 55 and was diagnosed as having PROMM at the age of 62. Needle electromyography and muscle biopsy supported the diagnosis. A gene study of the DM Type 1 showed a normal CTG repeat length. At age 63, he developed rest tremor, bradykinesia, hypomimia, stooped posture, and gait disturbance. The postural instability worsened rapidly. The tremor and rigidity were much worse in his right side, where myotonia was more severe. Levodopa therapy was only partially effective. Conclusion: This is a case report of a patient with PROMM that shows an association with a rapidly progressive form of parkinsonism. We suggest that this may be a novel form of a neurodegenerative disorder, which we name 'ParkinsonismMyotonic Myopathy-Complex'.
\end{abstract}

RÉSUMÉ: Un patient atteint de myopathie myotonique proximale et de parkinsonisme. Introduction: Il y a deux observations de patients atteints de myopathie myotonique proximale (MMPRO)/dystrophie myotonique (DM) de type 1 et de parkinsonisme rapportées dans la littérature. La combinaison d'une myopathie myotonique et de parkinsonisme est si rare qu'on peut penser qu'il s'agit d'une coïncidence. Cependant, l'examen anatomopathologique de tissus nerveux de patients atteints de dystrophie myotonique a montré qu'il y a des corps d'inclusion intracytoplasmiques dans la substance noire et le striatum, ce qui soulève la possibilité que la myopathie myotonique puisse être associée au parkinsonisme. Pour illustrer cette possibilité, nous décrivons le cas d'un patient atteint de MMPRO qui présentait cliniquement du parkinsonisme. Observation: Un homme âgé de 65 ans a développé de la faiblesse musculaire proximale, de la myotonie et de l'atrophie vers l'âge de 55 ans. Le diagnostic de MMPRO a été posé à 62 ans. Un électromyogramme et une biopsie musculaire ont confirmé le diagnostic. Une étude du gène de la DM de type 1 a montré une longueur normale du triplet CTG. À l'âge de 63 ans, il a développé un tremblement de repos, de la bradykinésie, de l'hypomimie, une posture voûtée et une démarche anormale. L'instabilité posturale a progressé rapidement. Le tremblement et la rigidité étaient beaucoup plus marqués du côté droit où la myotonie était plus sévère. Le traitement par la lévodopa n'a été que partiellement efficace. Conclusion: Nous rapportons le cas d'un patient atteint de MMPRO associée à une forme de parkinsonisme à progression rapide. Nous suggérons qu'il peut s'agir d'une forme nouvelle de désordre neurodégénératif que nous désignons sous le nom de "complexe myopathie myotonique-parkinsonisme".

Can. J. Neurol. Sci. 2002; 29: 188-190

Myotonic dystrophy (DM) is an autosomal dominant myotonic myopathy with systemic manifestations including frontal baldness, cataract, endocrine abnormalities, gonadal atrophy, ${ }^{1}$ and cognitive impairment. ${ }^{2-4}$ Neuropathological examination of patients' brains shows a reduced brain weight, and abnormalities in gyral architecture. Microscopically, there is
From the Department of Neurology and Clinical Research Institute (KC, J-WC, E-CS, BSJ), Seoul National University Hospital, Neuroscience Research Institute of SNUMRC. Seoul, Korea; and Department of Neurology (J-WC), College of Physicians and Surgeons, Columbia University, New York, USA.

ReCEIVEd July 6, 2001. ACCEPTED IN FinAL FORM NOVEMBER 21, 2001. Reprint requests to: Beom S. Jeon, Department of Neurology, Seoul National University Hospital, 28, Yongon-Dong, Chongno-Gu, Seoul 110-744, South Korea. 
a disordered cortical cellular arrangement with neurons in the subcortical white matter and intracytoplasmic inclusion bodies in the cerebral cortex, thalamus, striatum, and substantia nigra $(\mathrm{SN}){ }^{5-9}$ Involvement of the $\mathrm{SN}$ and striatum in DM suggests the possibility that parkinsonism may occur. Indeed there are two case reports of clinical parkinsonism associated with $\mathrm{DM}^{10}$ and proximal myotonic myopathy (PROMM). ${ }^{11}$ We presently report a second case of PROMM and clinically definite parkinsonism to highlight the possibility that PROMM may be associated with parkinsonism.

\section{CASE REPORT}

A 65-year-old man developed proximal muscle weakness, myotonia and muscle atrophy around the age of 55, and was diagnosed as having PROMM at age 62. He had the classical picture of PROMM showing frontal baldness, cataract, proximal muscle weakness, muscle pain, percussion and grip myotonia. A needle electromyography (EMG) showed myotonic discharges. A muscle biopsy showed findings that were consistent with myotonic myopathy. Electrocardiography showed normal findings. A gene study for DM Type 1 showed a normal CTG repeat length (repeat number $=24$ ) by the PCR technique. Southern blot analysis confirmed that the patient did not have DM1. At age 63, he developed rest tremor, cogwheel rigidity, bradykinesia, hypomimia, stooped posture, postural instability, and gait disturbance. The tremor and rigidity were much worse in his right side. Reportedly, his parents were neurologically normal at the time of their death but one of the two daughters was mildly affected. She had mild proximal muscle weakness, and myotonia but no evidence of parkinsonism. The gene study of the patient's daughter by polymerase chain reaction (PCR) test and southern blot analysis showed that CTG repeat length was normal. The cranial MRI of the patient showed mild atrophy of the cortex and brainstem and no white matter changes. There was no atrophy of putamen and caudate and no white matter changes. Levodopa (Madopar ${ }^{\circledR} 1200 \mathrm{mg}$ per day) was partially effective for relieving tremor and rigidity. Its true benefit might have been obscured by the myotonia. The postural instability worsened rapidly. By age 64, he fell frequently because of postural instability and he became bed-ridden. Around that time, he had a moderate cognitive decline with a flat affect; he had memory loss, and executive dysfunctions, as well as decreased verbal fluency. At age 65, he died suddenly at home during sleep, possibly because of cardiac arrhythmia. An autopsy was not done.

\section{Discussion}

The present case had a clinically defined PROMM, which was supported by EMG, clinical features, and muscle biopsy findings. Although a gene study for DM1 showed a normal CTG repeats length, there are several genes responsible for DM. The first genetic mutation discovered in DM was an expansion of the unstable CTG repeats in the 3' untranslated region of the myotonic dystrophy protein kinase (DMPK) gene in chromosome $19 q 13.3,{ }^{12-14}$ which was named DM1. Later, many families with autosomal dominant myotonic myopathy but without the CTG repeat expansion at the DM1 locus were found. ${ }^{15-18}$ Researchers at the University of Minnesota described a five-generation multisystemic myotonic disorder that closely resembled DM1, but had no CTG expansion. ${ }^{19,20}$ They called this disease "myotonic dystrophy type 2" (DM2; OMIM 602668), and mapped the DM2 locus to chromosome 3q. ${ }^{19}$ Other families who had an autosomal dominant myotonic myopathy but without CTG repeat expansion at the DM1 locus have some clinical differences from the DM1 disorder such as a predominant proximal involvement. Some of the families were linked to the DM2 locus. ${ }^{16,18,20,21}$ It is yet to be determined whether they represent different phenotypic expressions of the same mutation or have arisen from mutations in different genes that are closely linked to the DM2 locus. Because of the genetic heterogeneity in this group of disorders, a mere negative gene study for DM1 does not exclude a diagnosis of DM. Because the corresponding DM2 gene is not isolated, it is not possible to prove whether the patient has the DM2 locus or not.

Our patient is the third person known to have both parkinsonism and myotonic myopathy. The first case was reported by Okuma et al. ${ }^{10}$ The clinical manifestations in their patient showed typical features of parkinson's disease (PD) (i.e., asymmetric onset, a cogwheel rigidity, postural instability, bradykinesia, hypomimia and a sustained good response to levodopa). The disease ran for 13 years after the onset of the parkinsonism. The pathologic examination of his brain showed a marked loss of melanin-containing neurons and the presence of Lewy bodies in the SN, which is consistent with PD. There was no intracytoplasmic inclusion body in the brain. Gene studies confirmed the DM1 (the repeat length was 5,200). Their case could be just a coincidental occurence of PD and myotonic myopathy. The clinical manifestations in our patient have several different features from their case. First, the prominent postural instability occurred within the first year of the onset of the symptom. Second, the levodopa effect was only partial. Third, the progression of the parkinsonism was rapid. These features suggest that our patient's parkinsonism belongs rather to the parkinson-plus disorder rather than to PD. Hund et $\mathrm{al}^{11}$ reported a series of cases of PROMM, where there was a central nervous system involvement. One of their patients (no. 1-4) showed features of parkinsonism (e.g., hypomimia, stooped posture, gait disturbance, and hyphophonia) and no levodopa response. The D2 dopamine receptor SPECT with ${ }^{123}$ I-iodobenzamide showed a reduced uptake within the corpus striatum on both sides, which is unusual for PD. The clinical manifestations of our patient may resemble the latter case. ${ }^{11}$ It would have been helpful to perform an ${ }^{18} \mathrm{~F}$-Dopa PET, dopamine transporter, and D2 receptor imaging, and examine the involvement of the pre- and postsynaptic dopaminergic system.

This case report of a patient with PROMM shows an association with a rapidly progressive form of parkinsonism. We suggest that this may be a novel form of a neurodegenerative disorder, which we name 'Parkinsonism-Myotonic MyopathyComplex'.

\section{REFERENCES}

1. Harper PS. Myotonic Dystrophy, 2nd ed. Philadelphia, PA: Saunders, 1989.

2. Jaspert A, Fahsold R, Grehl H, Claus D. Myotonic dystrophy: correlation of clinical symptoms with the size of CTG trinucleotide repeat. J Neurol 1995;242:99-104.

3. Bird TD, Follet C, Griep E. Cognitive and personality function in myotonic muscular dystrophy. J Neurol Neurosurg Psychiatry 1983;46:971-980.

4. Chang L, Anderson T, Migneco A. Cerebral abnormalities in myotonic dystrophy: cerebral blood flow, magnetic resonance 
imaging, and neuropsychological tests. Arch Neurol 1993;50:917-923.

5. Rosman NP, Kakulas BA. Mental deficiency associated with muscular dystrophy: a neuropathological study. Brain 1966;89:769-788.

6. Wisniewsky HM, Berry K, Spiro AJ. Ultrastructure of thalamic neuronal inclusions in myotonic dystrophy. J Neurol Sci 1975;24:321-329.

7. Ono S, Inoue K, Mannen T, et al. Neuropathological changes of the brain in myotonic dystrophy: some new observations. J Neurol Sci 1987;81:310-320

8. Ono S, Inoue K, Mannen T, et al. Intracytoplasmic inclusion bodies of the thalamus and the substantia nigra, and the Marinesco bodies in myotonic dystrophy: a quantitative morphological study. Acta Neuropathol 1989;77:350-356.

9. Ono S, Takahashi K, Kanda F, et al. Immunohistochemical study of intracytoplasmic inclusion bodies of the thalamus in myotonic dystrophy. J Neurol Sci 1996;140:96-100.

10. Okuma Y, Tanaka S, Nomura Y, et al. A 63-year-old woman with muscle weakness, myotonia, and parkinsonism. No To Shinkei 1996;48:287-297. [Article in Japanese]

11. Hund E, Jansen O, Koch MC, et al. Proximal myotonic myopathy with MRI white matter abnormalities of the brain. Neurology 1997;48:33-37.

12. Aslandis C, Jansen G, Amemiya C, et al. Cloning of the essential myotonic dystrophy region and mapping of the putative defect. Nature 1992;355:548-551.

13. Buxton J, Shelbourne P, Davies J, et al. Detection of an unstable fragment DNA specific to individuals with myotonic dystrophy. Nature 1992;355:547-548.

14. Harley HG, Brook JD, Rundle SA, et al. Expansion of an unstable DNA region and phenotype variation in myotonic dystrophy. Nature 1992;355:545-546.

15. Thornton CA, Griggs RC, Moxley RT III. Myotonic dystrophy with no trinucleotide repeat expansion. Ann Neurol 1994;35:269-272.

16. Ricker K, Koch MC, Lehmann-Horn F. Proximal myotonic myopathy. Clinical features of a multisystem disorder similar to myotonic dystrophy. Arch Neurol 1995;52:25-31.

17. Meola F, Sansone V, Radice S, Skradski S, Ptacek L. Afamily with an unusual myotonic and myopathic phenotype and no CTG expansion (proximal myotonic myopathy syndrome): a challenge for future molecular studies. Neuromuscul Disord 1996;6:143-150.

18. Udd B, Krahe R, Wallgren-Pettersson C, Falck B, Kalimo H. Proximal myotonic dystrophy- a family with autosomal dominant muscular dystrophy, cataracts, hearing loss and hypogonadism: heterogeneity of proximal myotonic syndromes? Neuromuscul Disord 1997; 7:217-228.

19. Ranum LP, Rasmussen PF, Benzow KA, Koob MD, Day JW. Genetic mapping of a second myotonic dystrophy locus. Nat Genet 1998;19:196-198.

20. Day JW, Roelofs R, Leroy B, et al. Clinical and genetic characteristics of a five-generation family with a novel form of myotonic dystrophy (DM2). Neuromuscul Disord 1999;9:19-27.

21. The international myotonic dystrophy consortium (IDMC). New nomenclature and DNA testing guidelines for myotonic dystrophy type 1 (DM1). Neurology 2000;54:1218-1221. 